\title{
Orange Peel Essential Oil Nanoemulsions Supported by Nanosilver for Antibacterial Application
}

\author{
Doan Van Dat ${ }^{1, *}$, Nguyen Van Cuong ${ }^{1}$, Pham Hoang Ai Le ${ }^{1}$, Tran Thi Lan Anh ${ }^{1}$, \\ Pham Tan Viet ${ }^{2}$, and Nguyen Thi Lan Huong ${ }^{2}$
}

${ }^{1}$ Faculty of Chemical Engineering, Industrial University of Ho Chi Minh City, No. 12 Nguyen Van Bao, Ward 4, Go Vap District, Ho Chi Minh City 70000, Vietnam

${ }^{2}$ Institute of Biotechnology and Food Technology, Industrial University of Ho Chi Minh City, No. 12 Nguyen Van Bao, Ward 4, Go Vap District, Ho Chi Minh City 70000, Vietnam

\section{*Corresponding author:}

email: doanvandat@iuh.edu.vn

Received: May 22, 2019

Accepted: July 29, 2019

DOI: $10.22146 / \mathrm{ijc} .46042$

\begin{abstract}
This study is devoted to the synthesis of King Orange peel essential oil in water nanoemulsions combined with nanosilver by ultrasonic method supported by mechanical stirring for antibacterial application. The samples were characterized by Gas chromatography-mass spectrometry (GC-MS), Ultraviolet-visible (UV-Vis), Transmission electron microscopy (TEM), and Dynamic light scattering (DLS) methods. According to the above-experimental results, it was found that the emulsions based on orange essential oil (without nanosilver) and the ones combined with nanosilver have the average particle size from $66.2 \mathrm{~nm}$ and $42.9 \mathrm{~nm}$, respectively. The obtained nanoemulsions were also tested to examine their antibacterial ability against Escherichia coli (E. coli) by the disc diffusion method. It has been also found that nanoemulsions based on orange essential oil supported by nanosilver have the superior antibacterial ability, compared with individual components of the materials.
\end{abstract}

Keywords: nanoemulsions; orange peel essential oil; nanosilver; antibacterial application

\section{- INTRODUCTION}

In recent years, nanoemulsions based on plant essential oils are paid great attention because of their unique properties such as small droplet size (about 20$500 \mathrm{~nm})$, good stability, transparent appearance, and tunable rheology [1-4]. Therefore, they have been used widely in the cosmetic, pharmaceutical industries, food, and drug delivery, and antimicrobial applications [5-8].

Among high value plant essential oils, orange essential oil - scientific name of Citrus sinensis Osbeck, belonging to the family Rutaceae, has been one of the most widely used oils in the world, mainly extracted from cells in the orange peel, a few in the leaves and flowers. The main sweet aroma of the orange essential oil that can bring pleasant feeling, pleasant mood, and make people happy and cheerful is D-Limonene (90\%) [9]. Orange essential oil is also a natural antibacterial agent, which can inhibit the growth and eradication of E. coli, a very dangerous bacteria that causes kidney disease and might lead to death. In addition, the orange essential oil can inhibit the spread and development of Salmonella bacteria because it contains strong antimicrobial components, especially terpenes. In 2017, Lou et al. detailly reported the antimicrobial resistance of essential oils from citrus trees and indicated that citrus essential oil could inhibit the growth of $S$. aureus and E. coli [10].

Orange essential oil reveals less dissolve property in water. To enhance its solubility and stability properties of the oil, emulsion technology is one of the essential processes widely used for this purpose [11]. In the past decade, there has been a number of studies on nanomaterials based on essential oil form that showed their high effectiveness in food and health-protecting products applications. Li et al., in 2018, combined the citrus orange essential oil with chitosan to form 
microcapsules thanks to a variety of surfactants by gel ionic emulsion method to produce nanoemulsion particles larger than $289.3 \mathrm{~nm}$ [12]. Zhang et al., in 2016, reported the synthesis of nano clove essential oil and nano cinnamon essential oil with a particle size of $8.69 \mathrm{~nm}$ effective in antimicrobial resistance for Escherichia coli, Bacillus subtilis, Salmonella Typhimurium and Staphylococcus aureus [13]. Shahavi et al., in 2015, reported the optimal method of ultrasound for the synthesis of clove nano essential oil. This method gave the emulsion nanoparticles of size smaller than $50 \mathrm{~nm}$, stably distributed in the water environment [14]. Mehmood et al., in 2017, reported the optimum method to synthesis olive nano essential oil that produced the essential oil nanoparticles with a particle size of $151.68 \mathrm{~nm}$ [15]. Amrutha et al., in 2017, reported the synthesis of nano essential oil from Cuminum cynium and Pepper (Piper nirgrum). These essential oils were used in ultrasound to inhibit the activity of E. coli and S. enteria [16].

However, researches have been focused mainly on the efficient production of essential oils, the biological and chemical properties of essential oils extracting from nature, as well as the conversion of essential oils to nanoemulsion form. Nanoemulsions, supported by metal nanoparticles, namely, nanosilver for antibacterial applications, have not been widely reported. Only one article was found, in which Najafi-Taher et al. in 2018 reported a combination method of silver nanoparticleloaded tea tree oil nanoemulsion that showed a good antibacterial effect against E. coli and S. aureus [17]. Meanwhile, nanosilver is a material with a very large surface area, has the following unique characteristics such as disinfection, anti-fungus, deodorization, unharmful to human health at relatively high doses, ability to disperse stably in various solvents, high chemical stability, almost unchanged under the action of light and conventional oxidation-reduction agents [18].

Nanoemulsions are usually produced using highenergy emulsions, such as high-pressure homogenization, microfluidic diffusion, and high-intensity ultrasound [19]. Of these, the use of ultrasound to produce nanoemulsions becomes a recent trend [20]. Lower energy and surface stabilizer consumption, smaller particle size, higher dispersion, and higher stability of nanoemulsions are one of the main advantages of this technique over other methods [21]. To the best of our knowledge, nanosilver-loaded nanoemulsion based on King Orange essential oil from peel has not been reported yet. Therefore, the purpose of this work is devoted to synthesizing nanoemulsion based on essential oil from King Orange peel and combine it with silver nanoparticles by ultrasonic method for antimicrobial application.

\section{- EXPERIMENTAL SECTION}

\section{Materials}

The chemicals used for the synthesis of nanoemulsion are silver nitrate $\left(\mathrm{AgNO}_{3}, 99.8 \%\right)$, trisodium citrate $\left(\mathrm{Na}_{3} \mathrm{C}_{6} \mathrm{H}_{5} \mathrm{O}_{7} \cdot 2 \mathrm{H}_{2} \mathrm{O}, 99 \%\right)$, tween 80 $\left(\mathrm{C}_{64} \mathrm{H}_{124} \mathrm{O}_{26}, 99 \%\right)$, span $80\left(\mathrm{C}_{24} \mathrm{H}_{44} \mathrm{O}_{6}, 99 \%\right)$ of chemical reagent grade purchased from Shanghai Shenglong Chemical Co., China. Fresh orange peels were collected from King Orange (Citrus reticulata $\times$ Citrus sinensis) planted in southern Vietnam. Bidistilled water was used as a solvent for the preparation of all necessary solutions. The direct steam distillation method was used to extract the orange essential oil from orange peel.

\section{Procedure}

\section{Synthesis of nanoemulsion based on orange essential oil}

In this method, tween 80 and span 80 were selected as effective emulsifiers for the emulsion system; meanwhile, the dispersion process was conducted by the ultrasonic method supported by mechanical stirring according to the following procedure. A certain volume ratio of Tween 80 and Span 80 stabilizers $(0: 1 ; 0.25: 0.75$; $0.5: 0.5 ; 0.75: 0.25 ; 1: 0)$ were firstly taken into beakers, then different volume of orange essential oil ranging from 0.5 to $3 \mathrm{~mL}$ was added. The mixture was preliminarily stirred; after that, an appropriate amount of distilled water was poured slowly with a rate of 5 $\mathrm{mL} / \mathrm{min}$ into the mixture to get the total liquid volume of $50 \mathrm{~mL}$. The mixture was then homogenized by a mechanical stirrer for $10 \mathrm{~min}$ at a speed of $2100 \mathrm{rpm}$ and put under ultrasonic vibration in an ultrasonic 
Homogenizer Q500 Sonicator (Qsonica, USA) with an amplitude of $25 \%$ for $10 \mathrm{~min}$. The obtained emulsions were examined by the DLS method for particle size distribution on a Horiba SZ-100 analyzer (Horiba, Japan).

\section{Synthesis of nanosilver suspension}

In the past decades, there are many methods for the synthesis of nanosilver, in which chemical reduction is most commonly used. In this method, trisodium citrate was used as a reducing agent for the synthesis of silver nanoparticles because of low cost, simple synthesis, and easy to get silver nanoparticles with particle size in the range of $30-50 \mathrm{~nm}$ [22-23]. The synthesis procedure is as follows. $50 \mathrm{~mL}$ of $0.002 \mathrm{M} \mathrm{AgNO}_{3}$ solution was prepared in a flask that was wrapped totally by aluminum paper to protect from light, and $40 \mathrm{~mL}$ of $\mathrm{Na}_{3} \mathrm{C}_{6} \mathrm{H}_{5} \mathrm{O}_{7} 0.005 \mathrm{M}$ solution was also prepared in a $100 \mathrm{~mL}$ beaker. Both solutions were heated in a thermobath at the same time to get the temperature up to about $75-80{ }^{\circ} \mathrm{C}$. The $0.005 \mathrm{M}$ $\mathrm{Na}_{3} \mathrm{C}_{6} \mathrm{H}_{5} \mathrm{O}_{7}$ solution was then added slowly into $0.002 \mathrm{M}$ $\mathrm{AgNO}_{3}$ solution under stirring at $350 \mathrm{rpm}$. The mixture was then heated and kept at $85^{\circ} \mathrm{C}$ until the mixture turned to light yellow, stop heating, and cool down the mixture to room temperature. After synthesis, the suspension was stored in the dark to avoid the decomposition of silver nanoparticles by light.

\section{Method of combining nano essential oil with nanosilver 50 ppm suspension}

Orange peel essential oil nanoemulsions supported by nanosilver was synthesized similarly to orange peel essential oil nanoemulsion, in which the solution of 100 ppm silver nanoparticles served as stock solution was diluted by distilled water and used as dispersion media instead of pure water for combining nano essential oil with nanosilver, so that the final concentration of silver nanoparticles was unchanged and reached $50 \mathrm{ppm}$.

\section{Modern physico-chemical methods for studying composition, morphology and particle size of samples}

Gas chromatography-mass spectrometry (GC-MS) method was employed on an Agilent 7890a Series (Agilent, USA) for the examination of orange essential oil composition with evaporation temperatures for essential oil prior to analysis at 320 and $600{ }^{\circ} \mathrm{C}$. The particle size distribution and zeta potential were examined by dynamic light scattering (DLS) method using a Horiba SZ-100 nanoscale particle size analyzer (Horiba, Japan). The size of silver nanoparticles was determined by the transmission electron microscopy (TEM) method using a Jeol JEM-1400, Japan (Jeol, Japan). The Ultravioletvisible (UV-Vis) spectra of silver nanoparticles were determined on a UV-2450 (Shimadzu, Japan).

\section{Methods of antibacterial studies}

The antibacterial ability of samples was examined by the disc diffusion method for determining the susceptibility of Escherichia coli (E. coli) to orange peel essential oil nano-emulsions supported by nanosilver. Test procedure: the mentioned above bacteria were placed in a petri dish containing Luria Bertani agar; then, the bacteria were spread out of the agar surface. Six millimeters sterile paper disc was placed on the surface of the agar and then impregnated by $10 \mu \mathrm{L}$ of the test sample. A sample of antibiotics - ampicillin as positive evidence was also placed on the surface of the agar. The petri dish was covered by a sterile paper and kept at room temperature for 1-2 days. The rings surrounding antibacterial plates were observed for evaluating the antibacterial activity of the obtained samples. Orange essential oil, emulsion based on orange essential oil and silver nanoparticles suspension were used as blank samples for comparing their antibacterial activity with orange peel essential oil nanoemulsions supported by nanosilver. The antibacterial ability of all samples was tested at the Institute of Food and Biotechnology Industrial University of Ho Chi Minh City, Vietnam.

\section{- RESULTS AND DISCUSSION}

\section{Chemical Composition Analysis of Orange Peel Essential Oil by GC-MS Method}

The chemical composition of orange peel essential oil at two evaporation temperatures of 320 and $600{ }^{\circ} \mathrm{C}$ was presented in Table 1 .

From Table 1, it can be obviously seen that the main components of the King Orange peel essential oil are terpenium compounds (61-95\%), especially Limonene as major constituent of citrus fruits' essential oils [24]. Next is alcohol compounds $(0.3-5 \%)$, while the 
Table 1. The chemical composition of evaporated orange essential oil at 320 and $600{ }^{\circ} \mathrm{C}$

\begin{tabular}{|c|c|c|}
\hline \multirow{2}{*}{ Compounds } & $320^{\circ} \mathrm{C}$ & $600^{\circ} \mathrm{C}$ \\
\hline & \multicolumn{2}{|c|}{ Constituent content (\%) } \\
\hline a-Pinene & 0.54 & 0.45 \\
\hline$\beta$-Myricene & 0.24 & - \\
\hline (+)-Limonene & 75.79 & 61.64 \\
\hline Limonene oxide & 8.88 & 17.00 \\
\hline Cis-Carveol & 4.17 & 4.54 \\
\hline Carvone & 6.42 & 5.46 \\
\hline Cyclopentenone & 0.32 & - \\
\hline 1,4-Pentadiene & 0.24 & - \\
\hline 1,2-Cyclononadiene & 0.61 & - \\
\hline 1,9-Decadiyne & 1.85 & - \\
\hline E-p-Mentha-2,8-dienol & 0.94 & - \\
\hline Carhydrine & - & 3.67 \\
\hline Hexadenol & - & 0.34 \\
\hline Alloocimene & - & 0.67 \\
\hline 1,2-Pentadien & - & 1.97 \\
\hline 1,9-Decadiyne & - & 0.41 \\
\hline Ocimene & - & 0.41 \\
\hline Total & 100 & 99.98 \\
\hline
\end{tabular}

compounds of sesquiterpenes group occupy a very small part in the obtained oil (1 to 2.5\%). Espina et al., in 2013, described the good inactivation of E. coli by ( + )-limonene ( $97 \%$ purum) in detail and showed its potential in food preservation, either acting alone or in combination with other techniques [24].

\section{Analysis of Silver Nanoparticles Suspension}

Silver nanoparticles suspension obtained by the given method gets a light-yellow color, the higher the silver nanoparticles concentration, the darker the color of the solution.

An interesting phenomenon of nano metal particles called surface plasmon resonance is that each metal in nanosize absorbs electromagnetic radiation at a certain wavelength. The characteristics of this absorption vary depending on the size, shape, and structure of the particles and can be determined by UV-Vis spectra. For silver nanoparticles, the characteristic absorption peaks in the wavelength range around $425 \mathrm{~nm}$. UV-Vis spectrum of the 50-ppm silver concentration sample (Fig. 1) showed the peak absorption at $424.50 \mathrm{~nm}$, indicated the presence of silver nanoparticles in suspension [25].

TEM image analysis showed that silver nanoparticles in the obtained suspension were spherical with an average size of $40-50 \mathrm{~nm}$ (Fig. 2(a)). The DLS results of the silver nanoparticles suspension also confirmed the average nanosilver size of $42 \mathrm{~nm}$ (Fig. 2(b)).


Fig 1. UV-Vis spectrum of $50 \mathrm{ppm}$ nanosilver suspension
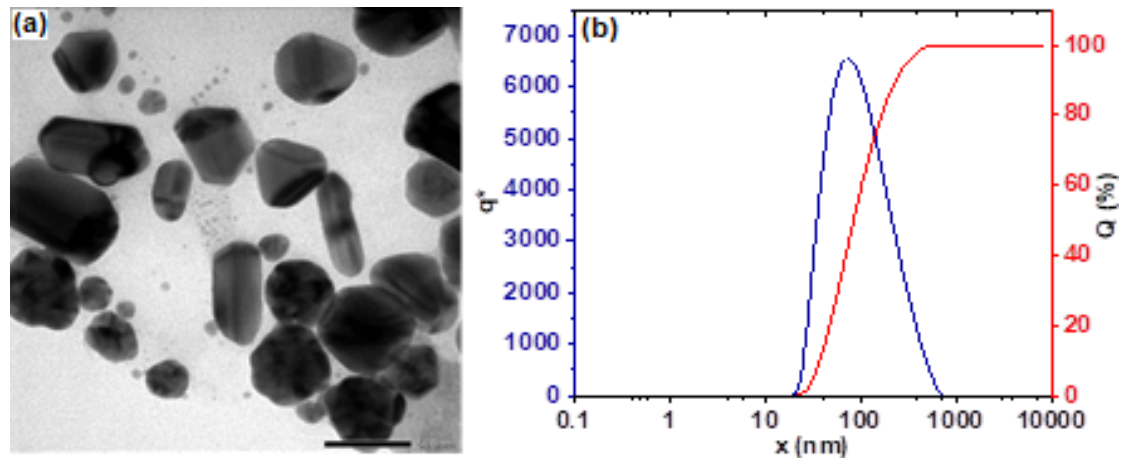

Fig 2. (a) TEM image of $50 \mathrm{ppm}$ nanosilver suspension; (b) Size distribution of silver nanoparticles in $50 \mathrm{ppm}$ silver nanoparticles suspension 
The similar results about the average size with $36-39 \mathrm{~nm}$ of nanosilver, synthesized by using trisodium citrate dihydrate as reductant were also found in [26].

\section{The Study of Emulsifier Selection}

The suitable emulsifiers can be selected based on their amphiphilic character characterized by the hydrophilic-lipophilic balance (HLB), firstly described by Griffin in 1949. The optimal stability of each nanoemulsion required a precise HLB value that could be given by mixing some surfactants, according to Griffin formula [27]. In this work, different mixtures of Span 80 with HLB $=4.3$ and Tween 80 with HLB $=15$ were applied to find out the appropriate HLB value for stabilization of nanoemulsion based on King Orange essential oil as follows. Various volume ratios of Tween 80 and Span 80 (0:1; 0.25:0.75; $0.5: 0.5 ; 0.75: 0.25 ; 1: 0)$ corresponded with HLB values of $4.24 ; 6.38 ; 9.63 ; 12.31 ; 15.00$ were mixed with $1 \mathrm{~mL}$ of orange oil and distilled water to get $50 \mathrm{~mL}$ suspension according to the described above procedure. The particle size distribution of 5 obtained samples after synthesis named B6-B10 was determined by the DLS method and presented in Table 2. The stability of the obtained samples had also been observed for 20 days (Fig. 3).

It has been found that all the samples of emulsion based on orange essential oil are nano-sized (Table 3). However, after 20 days, the lower part of sample B6 and sample B7 are lighter than the upper part of the bottle, indicating that the two samples are less stable due to the oil is lighter than the water, leading to floating up. The remaining three samples get better stability and have not yet been separated after 20 days (Fig. 3(b)). The experiment results also indicated that Tween 80 with the
HLB value of 15 is the best surface stabilizer for nanoemulsion based on orange essential oil production, as it retains the aroma of orange essential oil, high transparency, high stability and it gives the nanoemulsion with smallest particle size about $66 \mathrm{~nm}$ (Fig. 4). The obtained results are consistent with previous studies that emulsifiers with a small range of HLB values (4-6) generally stabilize water in oil nanoemulsions whereas higher HLB values above 8 would stabilize oil in water nanoemulsions [28-29].

\section{Combination of Nanoemulsion Based on Essential Oil with Nanosilver 50 ppm Suspension}

Orange essential oil with different volume from 0.5 to $3 \mathrm{~mL}$ was emulsified by Tween 80 (with a volume oil/emulsifier ratio of 2:3), $25 \mathrm{~mL} 100 \mathrm{ppm}$ nanosilver suspension, and an appropriate volume of distilled water to get $50 \mathrm{~mL}$ nanoemulsion with unchanged silver

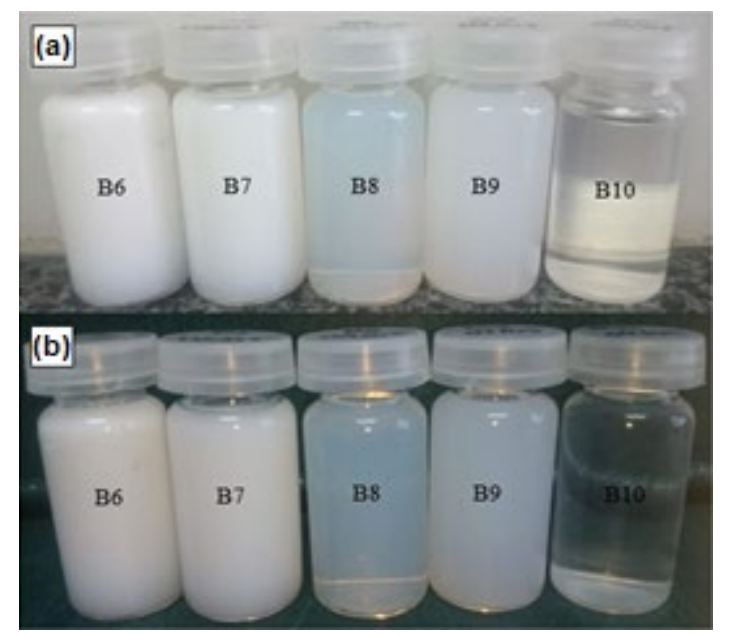

Fig 3. Nanoemulsions based on orange essential oil sample: (a) on first day, (b) after 20 days synthesis

Table 2. Particle size distribution of nanoemulsions based on orange essential oil with different ratio between tween 80 and span 80

\begin{tabular}{cccl}
\hline Sample & $\begin{array}{c}\text { Tween:Span } \\
{[\mathbf{m L}: \mathbf{m L})}\end{array}$ & $\begin{array}{c}\text { Average size } \\
{[\mathbf{n m}]}\end{array}$ & Observation \\
\hline B6 & $0: 1$ & 78.4 & White opaque, heavy smell of Span \\
B7 & $0.25: 0.75$ & 94.7 & White opaque, heavy smell of Span \\
B8 & $0.5: 0.5$ & 85.4 & White and slightly in clear, light orange smell \\
B9 & $0.75: 0.25$ & 106.1 & White opaque, light orange smell \\
B10 & $1: 0$ & 66.2 & Transparent, orange aromatic smell \\
\hline
\end{tabular}


nanoparticles concentration of $50 \mathrm{ppm}$. The obtained samples were named by D1 to D6, respectively. $50 \mathrm{ppm}$ nanosilver solution sample, which is named NB, plays the role of a blank sample for antibacterial test.

DLS results showed that the emulsion synthesis method of combination with nanosilver could be used to produce nanoemulsions with average particle size ranging from 42.9 to $135.5 \mathrm{~nm}$. The diagram indicated proportion of particle size distribution in the sample, in which the wider diagram, the lower the uniformity is. Compared to other works [30], the obtained DLS diagrams have narrow widths (Fig. 5); therefore, all the
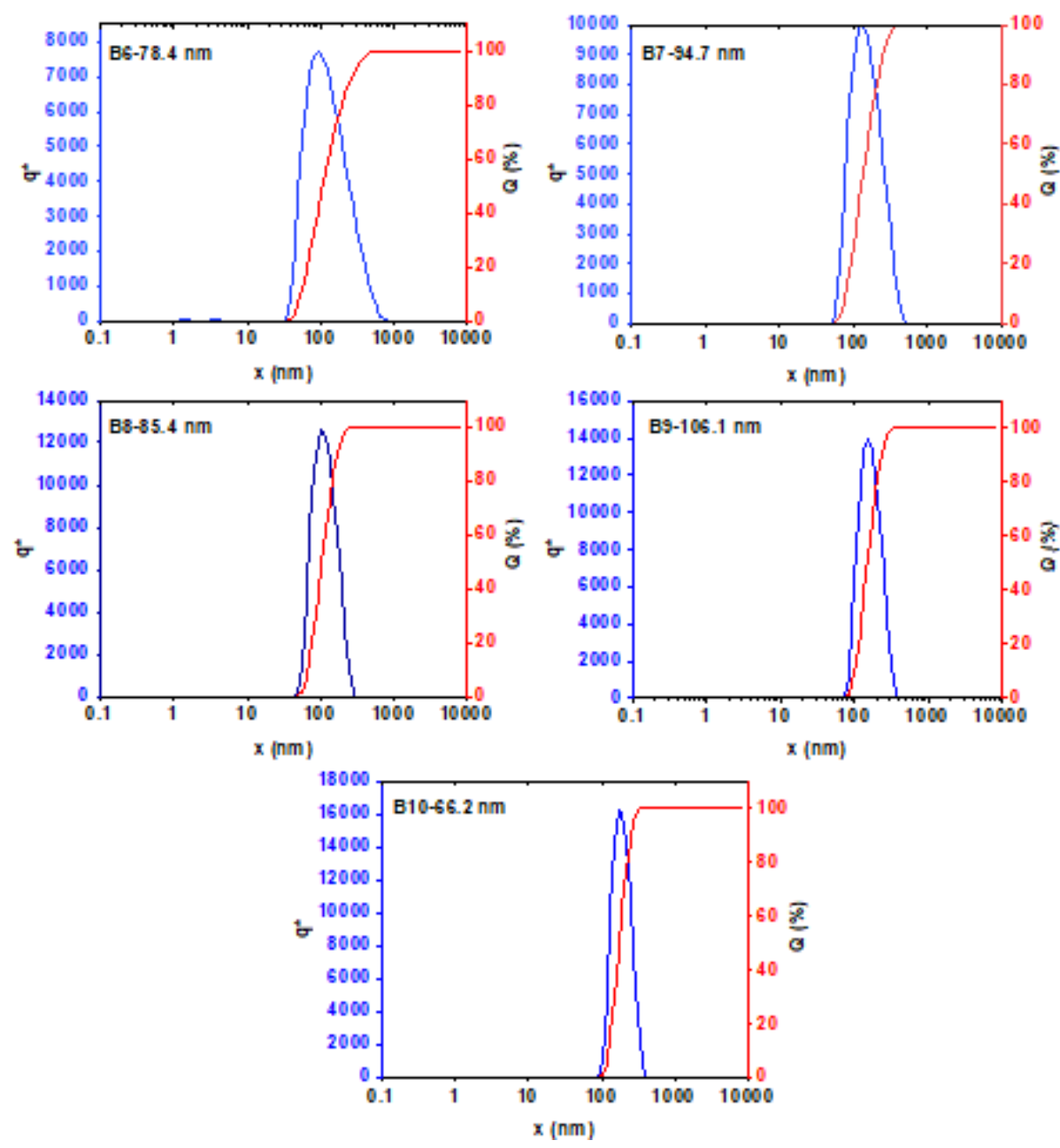

Fig 4. Particle size distribution of nanoemulsions based on orange essential oil only (without nanosilver)

Table 3. Particle size distribution of nanoemulsions based on orange essential oil combined with silver nanoparticles

\begin{tabular}{ccccc}
\hline Sample & $\begin{array}{c}\text { Orange essential } \\
\text { oil }(\mathbf{m L})\end{array}$ & $\begin{array}{c}\text { Silver nanoparticles } \\
\text { solution } \mathbf{1 0 0} \mathbf{p p m ~} \mathbf{~ m L}\end{array}$ & $\mathbf{H}_{\mathbf{2}} \mathbf{O}(\mathbf{m L})$ & Particle size (nm) \\
\hline D1 & 0.5 & 25 & 23.75 & 135.5 \\
D2 & 1 & 25 & 22.50 & 69.3 \\
D3 & 1.5 & 25 & 21.25 & 60.4 \\
D4 & 2 & 25 & 20.00 & 58.3 \\
D5 & 2.5 & 25 & 18.75 & 42.9 \\
D6 & 3 & 25 & 17.50 & 115.8 \\
NB & - & 25 & 25.00 & 42.7 \\
\hline
\end{tabular}

“-": the component was not added 

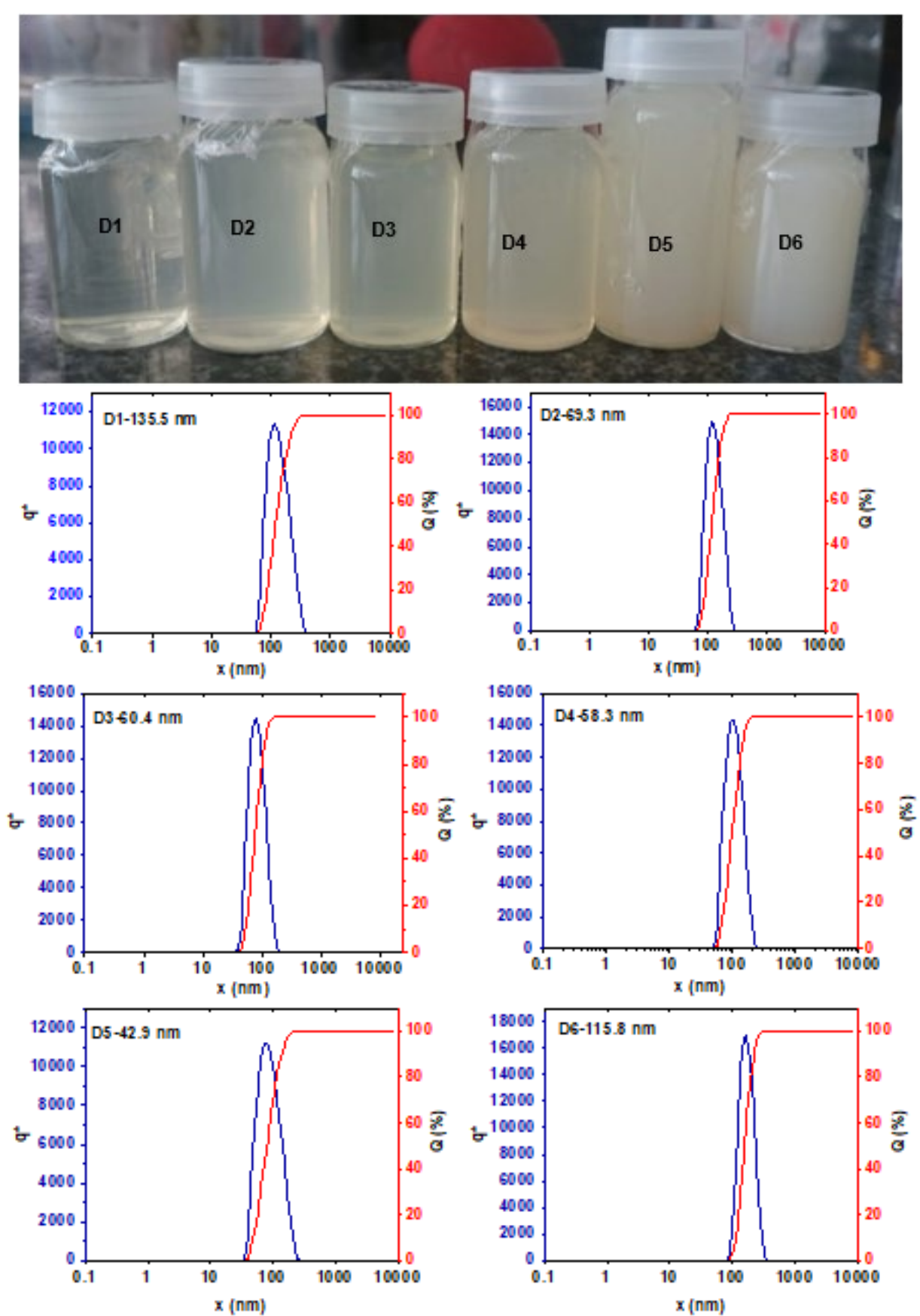

Fig 5. Nanoemulsions based on orange essential oil supported by silver nanoparticles with their particle size distribution

nanoemulsion samples have relatively high homogeneity, in which the D5 sample with $2.5 \mathrm{~mL}$ essential oil and 3.75 $\mathrm{mL}$ tween 80 as stabilizer has the smallest average particle size of $42.9 \mathrm{~nm}$. It has been found that the size of nanoemulsion particles tends to decrease with the addition of nanosilver. It could be explained that in the case without nanosilver, surfactant and oil together form a complex film at the oil water interface and thus generate emulsion droplets with hydrophobic tails bunched up, hydrophilic heads pointing towards the water [31]. In addition of nanosilver, nanosilver might be played the role of a hydrophobic core of emulsion 
droplet and attracted monolayer hydrophobic tails to form smaller nanoemulsion particles.

\section{Antibacterial Test for Nanoemulsions Based on Orange Essential Oil Combining with Silver Nanoparticles}

In the antibacterial test, $10 \mu \mathrm{L}$ of each sample was put onto a paper plate placed on the surface of the LB medium that contained E. coli bacteria. B6 to B10 samples are nanoemulsions based on orange essential oil combined with nanosilver $100 \mathrm{ppm}$ suspension. For comparison purposes, $50 \mathrm{ppm}$ nanosilver suspension sample, named NB and the nanoemulsions samples with different volumes of orange essential oils (without nanosilver), named D1 to D6, respectively - were also tested (Fig. 6).

It was observed that all the nanoemulsion samples based on orange essential oils are able to against E. coli bacteria, regardless of very low oil content. As combining with nanosilver, the antibacterial ability of the samples significantly increased, in which D3 sample with the average size of $60.4 \mathrm{~nm}$ and $1.5 \mathrm{~mL}$ orange oil has the greatest antibacterial ability, better than its individual components, although it is not the smallest particle size sample. It has been found that antibacterial ability of nanoemulsions based on orange essential oil combining

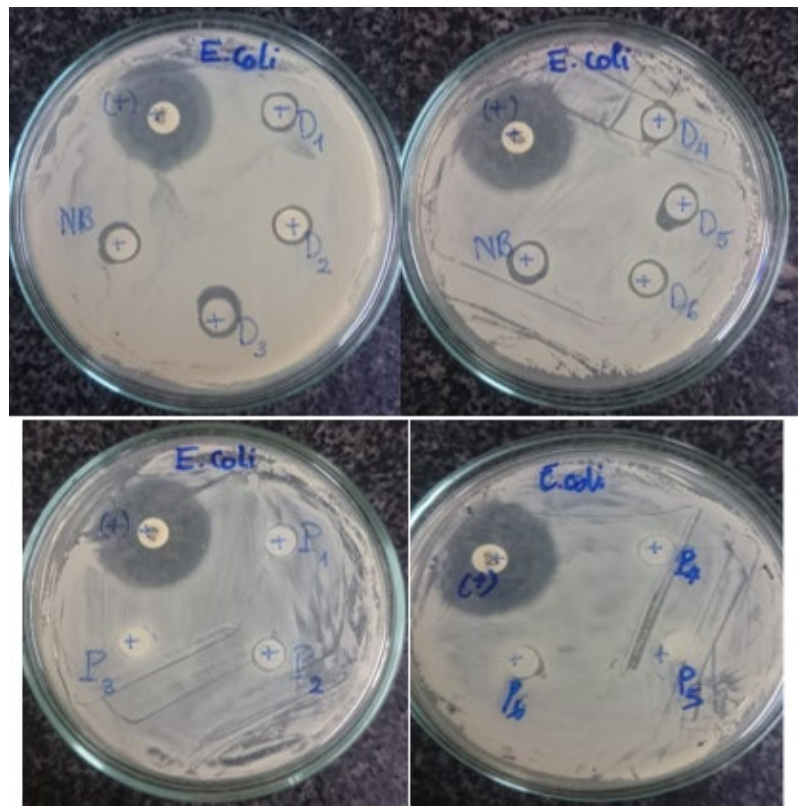

Fig 6. Antibacterial test against E. coli with silver nanoparticles depends on both particle size and the volume ratio between the oil and emulsifier. The addictive antibacterial mechanism of nanosilver-loaded nanoemulsion based on orange essential oil could be proposed as follows. Firstly, the essential oil layer with the main component consisted of limonene inactivated bacteria action by causing sub-lethal damages to the cytoplasmic or the outer membrane of bacteria [24]. Secondly, nanosilver acted with bacteria by linking disulfide (S-S) bridges in the enzyme structure of bacteria, disable this enzyme or break down bacterial cell membranes with oxidation reactions, resulting in bacteria destruction [32].

\section{- CONCLUSION}

Orange peel essential oil nanoemulsions combined with nanosilver was successfully synthesized by ultrasonic method supported by mechanical stirring, using tween 80 as an effective emulsifier. All the obtained samples are nanosized and revealed a good antibacterial capacity against E. coli. It has been also found that the antibacterial ability of nanoemulsions based on orange essential oil combining with silver nanoparticles depends not only on the particle size of individual components but also on the volume ratio between them.

\section{- ACKNOWLEDGMENTS}

This work was supported by scientific research project number 184.HH05 funded by the Industrial University of Ho Chi Minh city under contract No. 39/HD-DHCN.

\section{- REFERENCES}

[1] Hakemi-Vala, M., Rafati, H., Aliahmadi, A., and Ardalan, A., 2017, "Nanoemulsions: A Novel Antimicrobial Delivery System" in Nano- and Microscale Drug Delivery Systems, Eds. Grumezescu, A., Elsevier, London, 245-63.

[2] Ostróżka-Cieślik, A., and Sarecka-Hujar, B., 2017, "The Use of Nanotechnology in Modern Pharmacotherapy" in Multifunctional Systems for Combined Delivery, Biosensing and Diagnostics, Eds. Grumezescu, A., Elsevier, London, 139-158. 
[3] Bernardi, D.S., Pereira, T.A., Maciel, N.R., Bortoloto, J., Viera, G.S., Oliveira, G.C., and Rocha-Filho, P.A., 2011, Formation and stability of oil-in-water nanoemulsions containing rice bran oil: in vitro and in vivo assessments, J. Nanobiotechnol., 9, 44.

[4] Silva, J., Fernandes, A.R., and Baptista, P.V., 2014, Application of Nanotechnology in Drug Delivery, IntechOpen, London, 127-54.

[5] Amaral, D.M.F., and Bhargava, K., 2015, Essential oil nanoemulsions and food applications, Adv. Food Technol. Nutr. Sci., 1 (4), 84-87.

[6] Prakash, A., Vadivel, V., Rubini, D., and Nithyanand, P., 2019, Antibacterial and antibiofilm activities of linalool nanoemulsions against Salmonella Typhimurium, Food Biosci., 28, 57-65.

[7] Silva, H.D., Poejo, J., Pinheiro, A.C., Donsì, F., Serra, A.T., Duarte, C.M.M., Ferrari, G., Cerqueira, M.A., and Vicente, A.A., 2018, Evaluating the behaviour of curcumin nanoemulsions and multilayer nanoemulsions during dynamic in vitro digestion, $J$. Funct. Foods, 48, 605-613.

[8] Gupta, A., Eral, H.B., Hatton, T.A., and Doyle, P.S., 2016, Nanoemulsions: Formation, properties and applications, Soft Matter, 12 (11), 2826-2841.

[9] Milind, P., and Dev, C., 2012, Orange: Range of benefits, Int. Res. J. Pharm., 3 (7), 59-63.

[10] Lou, Z., Chen, J., Yu, F., Wang, H., Kou, X., Ma, C., and Zhu, S., 2017, The antioxidant, antibacterial, antibiofilm activity of essential oil from Citrus medica L. var. sarcodactylis and its nanoemulsion, LWT Food Sci. Technol., 80, 371-377.

[11] Anwer, M.K., Jamil, S., Ibnouf, E.O., and Shakeel, F., 2014, Enhanced antibacterial effects of clove essential oil by nanoemulsion, J. Oleo Sci., 63 (4), 347-354.

[12] Li, Y., Wu, C., Wu, T., Wang, L., Chen, S., Ding, T., and $\mathrm{Hu}, \mathrm{Y} ., 2018$, Preparation and characterization of citrus essential oils loaded in chitosan microcapsules by using different emulsifiers, J. Food Eng., 217, 108-114.

[13] Zhang, S., Zhang, M., Fang, Z., and Liu, Y., 2017, Preparation and characterization of blended cloves/cinnamon essential oil nanoemulsions, $L W T$ Food Sci. Technol., 75, 316-322.
[14] Shahavi, M.H., Hosseini, M., Jahanshahi, M., Meyer, R.L., and Darzi, G.N., 2016, Clove oil nanoemulsion as an effective antibacterial agent: Taguchi optimization method, Desalin. Water Treat., 57 (39), 18379-18390.

[15] Mehmood, T., Ahmad, A., Ahmed, A., and Ahmed, Z., 2017, Optimization of olive oil based O/W nanoemulsions prepared through ultrasonic homogenization: A response surface methodology approach, Food Chem., 229, 790-796.

[16] Amrutha, B., Sundar, K., and Shetty, P.H., 2017, Spice oil nanoemulsions: Potential natural inhibitors against pathogenic E. coli and Salmonella spp. from fresh fruits and vegetables, $L W T$ Food Sci. Technol., 79, 152-159.

[17] Najafi-Taher, R., Ghaemi, B., Kharrazi, S., Rasoulikoohi, S., and Amani, A., 2019, Promising antibacterial effects of silver nanoparticle-loaded tea tree oil nanoemulsion: A synergistic combination against resistance threat, AAPS PharmSciTech, 19 (3), 1133-1140.

[18] Deshmukh, S.P., Patil, S.M., Mullani, S.B., and Delekar, S.D., 2019, Silver nanoparticles as an effective disinfectant: A review, Mater. Sci. Eng., C, 97, 954-965.

[19] Rao, J., and McClements, D.J., 2011, Formation of flavor oil microemulsions, nanoemulsions and emulsions: Influence of composition and preparation method, J. Agric. Food Chem., 59 (9), 5026-5035.

[20] Li, P.H., and Chiang, B.H., 2012, Process optimization and stability of D-limonene-in-water nanoemulsions prepared by ultrasonic emulsification using response surface methodology, Ultrason. Sonochem., 19 (1), 192-197.

[21] Kentish, S., Wooster, T.J., Ashokkumar, M., Balachandran, S., Mawson, R., and Simons, L., 2008, The use of ultrasonics for nanoemulsion preparation, Innovative Food Sci. Emerg. Technol., 9 (2), 170-175.

[22] El-Nour, K.M.M.A., Eftaiha, A., Al-Warthan, A., and Ammar, R.A.A., 2010, Synthesis and applications of silver nanoparticles, Arabian J. Chem., 3 (3), 135-140. 
[23] Chowdhury, S., Yusof, F., Faruck, M.O., and Sulaiman, N., 2016, Process optimization of silver nanoparticle synthesis using response surface methodology, Procedia Eng., 148, 992-999.

[24] Espina, L., Gelaw, T.K., de Lamo-Castellví, S., Pagán, R., and García-Gonzalo, D., 2013, Mechanism of bacterial inactivation by (+)-limonene and its potential use in food preservation combined processes, PLoS One, 8 (2), e56769.

[25] Vo, T.T., Dang, C.H., Doan, V.D., Dang, V.S., and Nguyen, T.D., 2019, Biogenic synthesis of silver and gold nanoparticles from Lactuca indica leaf extract and their application in catalytic degradation of toxic compounds, J. Inorg. Organomet. Polym. Mater., 112.

[26] Ghazali, S., Jaafar, M., and Azizan, A., 2014, Synthesis of silver nanoparticles by chemical reduction method: Effect of reducing agent and surfactant concentration, IJAME, 105, 1920-1927.

[27] McClements, D.J., 2017, Nanoparticle- and Microparticle-based Delivery System: Encapsulation, Protection and Lease of Active Compounds, $1^{\text {st }}$ Ed., CRC Press, New York.
[28] Bos, M.A., and van Vliet, T., 2001, Interfacial rheological properties of adsorbed protein layers and surfactants: A review, Adv. Colloid Interface Sci., 91 (3), 437-471.

[29] Pichot, R., Spyropoulos, F., and Norton, I.T., 2010, $\mathrm{O} / \mathrm{W}$ emulsions stabilised by both low molecular weight surfactants and colloidal particles: The effect of surfactant type and concentration, J. Colloid Interface Sci., 352 (1), 128-135.

[30] Costa, I.C., Rodrigues, R.F., Almeida, F.B., Favacho, H.A., Falcão, D.Q., Ferreira, A.M., Vilhena, J.C.E., Florentino, A.C., Carvalho, J.C.T., and Fernandes, C.P., 2014, Development of jojoba oil (Simmondsia chinensis (Link) C.K. Schneid.) based nanoemulsions, Lat. Am. J. Pharm., 33 (3), 459-463.

[31] Kale, S.N., and Deore, S.L., 2017, Emulsion micro emulsion and nano emulsion: A review, Sys. Rev. Pharm., 8 (1), 39-47.

[32] Hajipour, M.J., Fromm, K.M., Ashkarran, A.A., de Aberasturi, D.J., de Larramendi, I.R., Rojo, T., Serpooshan, V., Parak, W.J., and Mahmoudi, M., 2012, Antibacterial properties of nanoparticles, Trends Biotechnol., 30 (10), 499-511. 